\title{
A 15-year longitudinal study on ambulatory blood pressure tracking from childhood to early adulthood
}

\author{
Zhibin $\mathrm{Li}^{1}$, Harold Snieder ${ }^{1,2,3}$, Gregory A Harshfield ${ }^{1}$, Frank A Treiber ${ }^{1,4}$ and Xiaoling Wang ${ }^{1}$
}

This study evaluates the tracking stability of office blood pressure (BP), ambulatory BP (ABP), BP variability (BPV) and nocturnal BP drops (dipping) from childhood to early adulthood, and their dependence on ethnicity, gender and family history (FH) of essential hypertension (EH). Generalized estimating equations (GEEs) were used to estimate tracking coefficients for 295 European Americans and 252 African Americans, with a maximum of 12 measurements over a 15-year period. Office BP and ABP had moderate-torelatively high tracking coefficients $(r=0.30-0.59 ; P \leqslant 0.001)$. Twenty-four hour readings tracked better than office readings for diastolic BP (DBP; 0.57 vs. $\left.0.46, P=1.72 \times 10^{-6}\right)$ and pulse pressure (PP) $\left(0.59\right.$ vs. $\left.0.51, P=2.70 \times 10^{-4}\right)$, and equally well for systolic BP (SBP; 0.55 vs. $0.54, P=0.805)$. Daytime readings tracked better than their night-time counterparts for SBP (0.50 vs. $\left.0.37, P=7.62 \times 10^{-13}\right)$, DBP $\left(0.49\right.$ vs. $\left.0.30, P=7.98 \times 10^{-32}\right)$ and PP $(0.55$ vs. $0.50, P=0.0061)$. All BPV $(r=0.08-0.28$; $P \leqslant 0.001)$ and dipping measures $(r=0.07-0.12$; odds ratio, $1.60-1.73 ; P \leqslant 0.001)$ had low tracking coefficients. Males had significantly higher tracking stability for office SBP, DBP and ambulatory PP than females $(P<0.01)$. Subjects with a positive FH of EH had significantly higher tracking stability for daytime and night-time DBP and dipping indexed by continuous variables than those with a negative FH $(P<0.001)$. No significant ethnic differences were observed. The high tracking stability of 24-h ABP highlights the importance of using ambulatory BP monitoring in both research and clinical settings.

Hypertension Research (2009) 32, 404-410; doi:10.1038/hr.2009.32; published online 27 March 2009

Keywords: ambulatory blood pressure; blood pressure variability; dipping; longitudinal study; tracking

\section{INTRODUCTION}

Tracking of a characteristic is defined as either the stability of a certain variable over time or the predictability of later values from earlier measurements. ${ }^{1,2}$ Longitudinal studies have shown significant office blood pressure (BP) tracking stability from childhood to adulthood, ${ }^{3-8}$ which is of considerable public health interest because children who are at high risk to develop adult hypertension might be identified at an early age. Although existing evidence suggests that ambulatory BP $(\mathrm{ABP})$ is superior to office $\mathrm{BP}$ as a predictor of target-organ damage and cardiac morbidity and mortality, ${ }^{9-13}$ little is known about the long-term tracking ability of $\mathrm{ABP}$, especially during the important transition period from childhood to early adulthood.

A non-invasive ABP monitor makes it possible to measure not only the ABP mean value, but also BP variability (BPV), which is generally estimated by the s.d. of ABP measures over $24 \mathrm{~h}$ and the separate subperiods of daytime and night time. Recently, BPV has been increasingly used as a predictor of target-organ damage and cardiovascular events; ${ }^{9,14-17}$ however, little is known about its stability over time.

A nocturnal BP drop is another interesting feature revealed by ABP. A large number of studies have reported that individuals with a blunted nocturnal decline in $\mathrm{BP}$, referred to as non-dippers, display the highest risk of target-organ damage and cardiovascular disease morbidity, ${ }^{18,19}$ because this pattern exposes these individuals to a greater cardiovascular load each day. Limited evidence is available on the reproducibility of the nocturnal BP drop. The evidence is conflicting: some studies show no reproducibility, ${ }^{20-24}$ whereas others indicate relatively good reproducibility. ${ }^{25-28}$ It should be noted that, in all of the available evidence, the nocturnal BP drop was studied across only two visits within a short period of follow-up, so evidence regarding tracking of the nocturnal BP drop from multiple visits with a longer period of follow-up is needed.

In this study of 295 European American (EA) and 252 African American (AA) youths evaluated up to 12 times over a 15-year period from childhood to early adulthood, we examined and contrasted the tracking ability of office $\mathrm{BP}$ and $\mathrm{ABP}$, as well as the tracking stability of BPV and the nocturnal BP drop. We further determined the extent to which these tracking stabilities may depend on gender, ethnicity and family history $(\mathrm{FH})$ of essential hypertension (EH).

\section{METHODS}

Study population

Subjects were selected from participants $(n=745)$ in an ongoing longitudinal study evaluating the development of cardiovascular risk factors in youth. ${ }^{29,30}$ The data encompass a 15-year period (1989-2004) in which 12 assessments were conducted. The data set is complicated because not all subjects had the

\footnotetext{
${ }^{1}$ Department of Pediatrics, Medical College of Georgia, Georgia Prevention Institute, Augusta, GA, USA; ${ }^{2}$ Unit of Genetic Epidemiology and Bioinformatics, Department of Epidemiology, University Medical Center Groningen, University of Groningen, The Netherlands; '3King's College London, Twin Research and Genetic Epidemiology Unit, St Thomas' Campus, London, UK and ${ }^{4}$ Department of Psychiatry, Medical College of Georgia, Augusta, GA, USA Correspondence: Dr X Wang, Department of Pediatrics, Medical College of Georgia, Georgia Prevention Institute, Building HS-1640, Augusta, GA 30912, USA. E-mail: xwang@mcg.edu
}

Received 14 November 2008; revised 21 January 2009; accepted 10 February 2009; published online 27 March 2009 
same number of visits; subjects were recruited into the study at different ages and in different years. Of the 745 subjects, 547 participants were included in this study based on the following criteria: (1) valid readings for both office and $\mathrm{ABP}$ and (2) at least two visits during the 15 -year period. No significant difference in either office BP or ABP was found between individuals who qualified for this study and those who were excluded. The median age at the first visit was 14.1 years (range: $7.4-27.4 ; 25-75 \%$ : 12.2-16.2), and the median age at the last visit was 20.1 years (range: $11.4-29.5 ; 25-75 \%: 18.4-22.1$ ). The median follow-up period was 5.8 years (range: $0.8-18 ; 25-75 \%$ : $3.6-7.9$ ). The number of subjects with different numbers of office and ABP assessments is shown in Supplementary Table 1 . More than $60 \%$ of participants had $\geqslant 4$ visits, making this data set very informative for the study of BP tracking over time.

Subject recruitment, evaluation, classification and attrition rate have been described earlier. ${ }^{29}$ Briefly, recruitment and evaluation of subjects began in 1989. Participants who met the following criteria were recruited: (1) 7-16 years old in 1989; (2) AAs or EAs; (3) normotensive for age and gender based on BP screening; and (4) apparently healthy based on parental reports of medical history. The annualized attrition rate was $<4 \%$ per year. There were no significant differences in age, ethnicity or gender distribution between dropouts and the subjects who remained in the study. A positive $\mathrm{FH}$ of $\mathrm{EH}$ was defined as the occurrence of $\mathrm{EH}$ in one or both biological parents at any visit. The diagnosis of EH was verified by the physician or medical records. ${ }^{29}$ Eleven subjects began to take antihypertensive medication during the study, and the data obtained during this period were excluded from analyses. The Institutional Review Board at the Medical College of Georgia gave approval for the study, and informed consent was obtained from one of the parents and from the child.

\section{Measurements}

Office BP recordings. At each annual laboratory visit during the 15-year period, both anthropometric and cardiovascular evaluations were conducted. ${ }^{29,31,32}$ Subjects' height and weight were measured with a Healthometer medical scale that was calibrated daily. Body mass index (BMI) was calculated as a measure of general obesity. Office systolic BP (SBP) and diastolic BP (DBP) were measured with the Dinamap Vital Signs Monitor (model 1864 SX; Criticon Incorporated, Tampa, FL, USA). Cuff size was selected according to mid-arm circumference $(12-19,17-25,23-33,31-40$ and $38-50 \mathrm{~cm})$. BP measurements were taken at the 11th, 13th and 15th minutes of a 15-min supine relaxation period. The average of the last two readings was used to represent SBP and DBP values. Pulse pressure (PP) was defined as the difference between SBP and DBP (SBP-DBP).

Ambulatory BP recordings. Our procedures for ABP recordings have been described earlier in detail. ${ }^{30,33}$ Briefly, an ABP monitor was fitted to the nondominant arm (model 90207, SpaceLabs, Redmond, WA, USA). Cuff size was selected according to mid-arm circumference (12-20, 17-26, 24-32, 32-42 and $38-50 \mathrm{~cm})$. Measures were obtained every $20 \mathrm{~min}$ during the day $(0800-2200$ hours) and every $30 \mathrm{~min}$ at night (2400-0600 hours). Transitional periods from 0600 to 0800 hours and from 2200 hours to midnight were not included in the analyses. Adequacy of the recordings was based on acceptable readings using previously established criteria ${ }^{33}$ for $\geqslant 14$ readings over the $14 \mathrm{~h}$ designated as daytime and $\geqslant 6$ readings over the $6 \mathrm{~h}$ designated as the night time, as suggested by the European Society of Hypertension Working Group on Blood Pressure Monitoring. ${ }^{34}$ Mean values of SBP, DBP and PP for 24-h daytime and night-time subperiods were used as indices of $\mathrm{ABP}$ recordings.

BP variability. BP variability was indexed by the s.d. of the ABP recordings over the entire 24-h period and separately for daytime and night-time subperiods. In addition, to account for the influence of the nocturnal BP fall on the 24-h BP s.d., and to quantify $24-\mathrm{h} \mathrm{BPV}$ without the circadian component, the weighted 24-h BP s.d. was also used in this study, which is the mean of the daytime and night-time s.d. weighted for the duration of the daytime and nighttime subperiods. ${ }^{35}$

Nocturnal BP fall (dipping). Three indices of the nocturnal BP drop were used in this study. First, the difference between daytime and night time was evaluated. Second, the night-time BP drop expressed as a proportion of the daytime value was evaluated ((daytime-night time)/daytime). Third, subjects were classified into two categories: those whose night-time BP fell more than $10 \%$ of the daytime values (dippers) and those in whom it fell less (non-dippers). ${ }^{12}$

\section{Statistical analyses}

Tracking coefficients were estimated using the following multivariate linear regression model.

$$
Y_{i t}=\beta_{0}+\beta_{1} Y_{i t 1}+\beta_{2 t}+\sum_{j=1}^{j} \beta_{3 j} X_{i j t}+\sum_{k=1}^{k} \beta_{4 k} Z_{i k}+\varepsilon_{i t}
$$

$Y_{i t}$ is the dependent variable (which, in our study, may be office BP, ABP, BPV or dipping) for individual $i$ from $t_{2}$ to $t_{m}$ (where $m$ is the number of measurements). $Y_{i t 1}$ is the initial observation of individual $i$ at $t_{1}$ (t=time). $X_{i j t}$ is the time-dependent covariate $j$ for individual $i . Z_{i k}$ is the timeindependent covariate $k$ for subject $i . \varepsilon_{i t}$ is the measurement error for individual $i$.

In this model, the initial measurement of the dependent variable $Y$ at time $t_{1}$ (for example, office SBP reading on the first visit) is regressed on the same variable $Y$ from time $t_{2}$ to $t_{m}$. $\beta_{1}$ is the standardized regression coefficient of the initial measurement of the dependent variable, which can be interpreted as the average tracking coefficient across the duration of the study. ${ }^{36}$ A logistic regression model can be used to quantify tracking of a dichotomous variable (for example, dipper vs. non-dippers). In this case, the coefficient $\beta_{1}$ can be transformed into an odds ratio, which gives the magnitude of the 'odds' of a subject belonging to a group at $t_{1}$, with regard to the development of the subject's group status from $t_{2}$ to $t_{m}$ relative to the 'odds' of a subject not belonging to that group at $t_{1 .}{ }^{36}$

This model has several advantages compared with other tracking models. First, it can handle missing values of the dependent variable, so a balanced data set is not required. Second, the use of covariates allowed us to adjust for possible confounders. In the present analysis, ethnicity, gender, $\mathrm{FH}$ of $\mathrm{EH}$, age of the subjects' initial visit and age of the subjects at follow-up visits were included as covariates.

To contrast tracking ability between office BP and 24-h BP or between daytime and night-time $\mathrm{BP}$, we calculated the test statistic $Z=\left(\beta_{1}-\beta_{2}\right) / \sqrt{\left(\text { s.e. } 1 \times \beta_{1}\right)^{2}+\left(\text { s.e. } 2 \times \beta_{2}\right)^{2}}$ which approximately follows a standard normal distribution, where $\beta_{1}$ and $\beta_{2}$ are standardized regression coefficients for different BP measurements, and s.e. 1 and s.e. 2 are s.e. for $\beta_{1}$ and $\beta_{2}$, respectively. ${ }^{37} \mathrm{~A}$ Bonferroni correction for multiple comparisons $(n=6)$ was applied, and a value of $P<0.008$ was deemed statistically significant for this comparison.

For the tracking of BPV, mean $\mathrm{ABP}$ values were also included as a covariate. To investigate whether there was a significant effect of ethnicity, gender or FH of $\mathrm{EH}$ on tracking stability, the interaction terms among ethnicity, gender, $\mathrm{FH}$ of $\mathrm{EH}$ and $Y_{i t 1}$ were tested. In an alternative model, BMI, height, weight and heart rate were further added to the model separately. To control for dependence between repeated observations in the same subjects, we used generalized estimating equations (GEEs), which yield unbiased s.e. and $P$-values. ${ }^{36}$ For the dichotomous variable of nocturnal BP drop, a GEE analysis for dichotomous outcome variables was used. ${ }^{36}$ All analyses were performed using STATA 8.0 (StataCorp, College Station, TX, USA).

\section{RESULTS}

The baseline (first visit) characteristics of demographics, office BP, ABP, BPV and dipping by ethnicity and gender are shown in Table 1. For the mean values of office BP and ABP, males had higher SBP and PP than females, whereas AAs had higher SBP and DBP than EAs. For BPV, males had higher levels in both SBP and DBP during 24-h, daytime and weighted 24-h periods, whereas AAs had higher values of DBP during daytime, night-time, and weighted 24-h periods. For the nocturnal BP drop, EAs had a higher prevalence of dippers than AAs.

After adjustment for age, gender, ethnicity and $\mathrm{FH}$ of $\mathrm{EH}$ (with additional adjustment for mean ABP values for BPV measures), the 
Table 1 Characteristics of subjects' first visit by ethnicity and gender

\begin{tabular}{|c|c|c|c|c|c|c|}
\hline & \multicolumn{2}{|c|}{$E A$} & \multicolumn{2}{|c|}{$A A$} & \multicolumn{2}{|c|}{ P-value } \\
\hline & Males & Females & Males & Females & Gender & Ethnicity \\
\hline$n$ & 156 & 139 & 107 & 145 & & \\
\hline Age, years & $14.2 \pm 3.1$ & $14.4 \pm 3.1$ & $14.2 \pm 3.0$ & $14.4 \pm 3.2$ & NS & NS \\
\hline Family history of $\mathrm{EH}, \%$ & 65.4 & 64.5 & 84.1 & 88.7 & NS & $<0.001$ \\
\hline \multicolumn{7}{|l|}{ Anthropometrics } \\
\hline Height, cm & $162.8 \pm 16.3$ & $158.1 \pm 11.2$ & $162.2 \pm 14.1$ & $159.2 \pm 10.9$ & $<0.001$ & NS \\
\hline Weight, kg & $58.5 \pm 19.3$ & $56.6 \pm 17.4$ & $61.2 \pm 22.1$ & $63.5 \pm 22.4$ & NS & $<0.01$ \\
\hline $\mathrm{BMI}, \mathrm{kg} / \mathrm{m}^{2}$ & $21.4 \pm 4.5$ & $22.3 \pm 5.3$ & $22.6 \pm 5.6$ & $24.7 \pm 7.3$ & $<0.01$ & $<0.001$ \\
\hline \multicolumn{7}{|l|}{ Office $B P, \mathrm{~mm} \mathrm{Hg}$} \\
\hline \multicolumn{7}{|l|}{$A B P, m m H g$} \\
\hline 24-h SBP & $115.1 \pm 7.7$ & $111.3 \pm 6.6$ & $117.7 \pm 9.0$ & $113.6 \pm 7.1$ & $<0.001$ & $<0.001$ \\
\hline 24-h DBP & $66.2 \pm 4.6$ & $65.9 \pm 5.0$ & $68.1 \pm 5.9$ & $68.0 \pm 5.2$ & NS & $<0.001$ \\
\hline 24-h PP & $48.9 \pm 6.8$ & $45.5 \pm 4.5$ & $49.6 \pm 7.3$ & $45.6 \pm 5.3$ & $<0.001$ & NS \\
\hline Daytime SBP & $119.4 \pm 8.5$ & $115.5 \pm 7.4$ & $121.4 \pm 9.6$ & $117.2 \pm 7.9$ & $<0.001$ & $<0.05$ \\
\hline Daytime DBP & $70.8 \pm 5.9$ & $70.6 \pm 6.4$ & $72.5 \pm 7.0$ & $72.1 \pm 6.1$ & NS & $<0.01$ \\
\hline Daytime PP & $48.6 \pm 7.0$ & $44.9 \pm 4.4$ & $48.9 \pm 7.6$ & $45.1 \pm 5.5$ & $<0.001$ & NS \\
\hline Night-time SBP & $107.4 \pm 8.9$ & $104.1 \pm 8.0$ & $110.8 \pm 9.9$ & $106.8 \pm 8.1$ & $<0.001$ & 0.001 \\
\hline Night-time DBP & $57.9 \pm 6.8$ & $57.7 \pm 5.8$ & $60.2 \pm 6.9$ & $60.3 \pm 7.0$ & NS & $<0.001$ \\
\hline Night-time PP & $49.5 \pm 7.6$ & $46.4 \pm 5.4$ & $50.7 \pm 8.2$ & $46.4 \pm 6.1$ & $<0.001$ & NS \\
\hline \multicolumn{7}{|l|}{$B P V, m m ~ H g$} \\
\hline Weighted 24-h DBP s.d. & $9.1 \pm 1.8$ & $8.4 \pm 1.7$ & $9.5 \pm 2.0$ & $9.3 \pm 2.0$ & $<0.01$ & $<0.001$ \\
\hline \multicolumn{7}{|l|}{ Dipping } \\
\hline Day-night SBP, mm Hg & $12.1 \pm 8.3$ & $11.4 \pm 7.6$ & $10.6 \pm 7.8$ & $10.4 \pm 7.8$ & NS & NS \\
\hline Day-night DBP, mm Hg & $13.0 \pm 8.4$ & $12.9 \pm 6.9$ & $12.3 \pm 7.5$ & $11.8 \pm 8.1$ & NS & NS \\
\hline (Day-night)/day SBP, \% & 9.9 & 9.7 & 8.6 & 8.7 & NS & NS \\
\hline (Day-night)/day DBP, \% & 17.8 & 17.8 & 16.6 & 16.0 & NS & NS \\
\hline Dipper for SBP, \% & 57.1 & 54.0 & 44.9 & 43.4 & NS & $<0.01$ \\
\hline Dipper for DBP, \% & 84.0 & 85.6 & 77.6 & 76.6 & NS & $<0.05$ \\
\hline
\end{tabular}

Abbreviations: AA, African American; ABP, ambulatory blood pressure; BMI, body mass index; BPV, blood pressure variability; DBP, diastolic blood pressure; EA, European American; EH, essential hypertension; NS, not significant; PP, pulse pressure; SBP, systolic blood pressure.

Values are mean \pm s.d.

tracking coefficients and their 95\% confidence intervals (CIs) for office BP, ABP, BPV and dipping are shown in Table 2. The tracking coefficients of office $\mathrm{BP}$ and $\mathrm{ABP}$ measures ranged from $0.30-0.59$ $(P \leqslant 0.001)$, which indicated moderate-to-relatively high stability of tracking. In all, 24-h readings tracked better than office readings for DBP $\left(0.57\right.$ vs. $\left.0.46, P=1.72 \times 10^{-6}\right)$ and $\mathrm{PP}(0.59$ vs. 0.51 , $\left.P=2.70 \times 10^{-4}\right)$, whereas they tracked equally well for SBP (0.55 vs. $0.54, P=0.805$ ). Daytime readings tracked better than their night-time counterparts for SBP $\left(0.50\right.$ vs. $\left.0.37, P=7.62 \times 10^{-13}\right)$,
DBP $\left(0.49\right.$ vs. $\left.0.30, P=7.98 \times 10^{-32}\right)$ and PP ( 0.55 vs. $\left.0.50, P=0.0061\right)$. Additional adjustments for other potential confounders (BMI, height, weight and heart rate separately) did not change the results (data not shown).

Tracking coefficients for all measures of BPV were lower than 0.30 (range: $0.08-0.28, P \leqslant 0.001$ ), indicating that BPV was not very stable over time.

For the nocturnal BP drop, both the absolute value of the difference between daytime and night time, and the night-time drop expressed as 
Table 2 Tracking coefficients of office BP, ABP, BPV and nocturnal BP fall (dipping) in all subjects

\begin{tabular}{|c|c|c|c|}
\hline & $\begin{array}{c}S B P \\
\text { Tracking coefficient }(95 \% \mathrm{Cl})\end{array}$ & $\begin{array}{c}D B P \\
\text { Tracking coefficient }(95 \% \mathrm{Cl})\end{array}$ & $\begin{array}{c}P P \\
\text { Tracking coefficient }(95 \% \mathrm{Cl})\end{array}$ \\
\hline Office BPa & $0.54(0.49,0.60)$ & $0.46(0.41,0.51)$ & $0.51(0.46,0.56)$ \\
\hline $24 \mathrm{~h}$ & $0.55(0.50,0.60)$ & $0.57(0.51,0.62)$ & $0.59(0.53,0.64)$ \\
\hline Daytime & $0.50(0.45,0.55)$ & $0.49(0.44,0.55)$ & $0.55(0.50,0.60)$ \\
\hline Night time & $0.37(0.31,0.42)$ & $0.30(0.23,0.36)$ & $0.50(0.44,0.55)$ \\
\hline \multicolumn{4}{|l|}{$B P V^{\mathrm{b}}$} \\
\hline 24-h s.d. & $0.20(0.14,0.25)$ & $0.28(0.22,0.33)$ & - \\
\hline Daytime s.d. & $0.08(0.02,0.13)$ & $0.21(0.15,0.26)$ & - \\
\hline Night-time s.d. & $0.08(0.03,0.13)$ & $0.11(0.06,0.16)$ & - \\
\hline Weighted 24-h s.d. & $0.09(0.04,0.15)$ & $0.21(0.16,0.27)$ & - \\
\hline \multicolumn{4}{|l|}{ Dipping ${ }^{a}$} \\
\hline
\end{tabular}

Abbreviations: ABP, ambulatory blood pressure; BPV, blood pressure variability; DBP, diastolic blood pressure; PP, pulse pressure; SBP, systolic blood pressure. $P$-value for tracking coefficients is $\leqslant 0.001$. Tracking coefficient is the standardized regression coefficient for continuous variables.

aAll the tracking coefficients were adjusted for age, gender, ethnicity and family history of essential hypertension.

${ }^{b}$ All the tracking coefficients were adjusted for age, gender, ethnicity, family history of essential hypertension and mean BP.

cOdds ratio for dichotomous dipping (dipper: those whose night-time BP drop is $>10 \%$ of the daytime values; non-dipper: those whose night-time BP drop is $<10 \%$ of the daytime values)

Table 3 Tracking coefficients of office BP, ABP and BPV by gender

\begin{tabular}{lccc}
\hline & \multicolumn{2}{c}{ Male } & \multicolumn{1}{c}{ Female } \\
\cline { 2 - 3 } & Tracking coefficient $(95 \% \mathrm{Cl})$ & P-value & Tracking coefficient (95\% Cl) \\
\hline $\begin{array}{l}\text { Office BPa } \\
\text { SBP }\end{array}$ & $0.62(0.54,0.70)$ & $<0.001$ & $0.51(0.43,0.59)$ \\
DBP & $0.50(0.42,0.57)$ & $<0.001$ & $0.44(0.36,0.51)$ \\
ABPa & & & $<0.001$ \\
24-h PP & $0.73(0.64,0.83)$ & $<0.001$ & $0.64(0.57,0.71)$ \\
Daytime PP & $0.69(0.60,0.79)$ & $<0.001$ & $0.58(0.51,0.66)$ \\
Night-time PP & $0.58(0.49,0.67)$ & $<0.001$ & $0.54(0.46,0.62)$ \\
BPV & & & $<0.001$ \\
Weighted 24-h SBP s.d. & $0.05(-0.03,0.13)$ & $\mathrm{NS}$ & $<0.001$ \\
\hline
\end{tabular}

Abbreviations: ABP, ambulatory blood pressure; BPV, blood pressure variability; DBP, diastolic blood pressure; PP, pulse pressure; SBP indicates systolic blood pressure.

Tracking coefficient is the standardized regression coefficient.

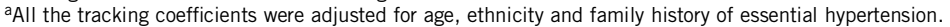

bAll the tracking coefficients were adjusted for age, ethnicity, 24-h mean SBP and family history of essential hypertension.

a proportion of the daytime BP had low tracking coefficients (range: $0.07-0.12$ ). When subjects were classified as dippers $v s$. non-dippers, the tracking stability indexed by the odds ratio (range: 1.60-1.73) was also quite low. These results indicated that nocturnal BP drop was not stable over time, regardless of the index used.

Males had significantly higher tracking stability of office SBP, office DBP and ambulatory PP, but lower tracking stability on weighted 24-h s.d. of SBP than females (Table 3, Ps $<0.01$ ). Subjects with a positive FH of EH had significantly higher tracking of daytime and night-time DBP as well as the nocturnal BP drop in comparison with subjects with a negative $\mathrm{FH}$ (Table $4, P_{\mathrm{s}} \leqslant 0.001$ ). No significant ethnic differences in tracking stability of office BP, ABP, BPV and dipping were found (data not shown).

\section{DISCUSSION}

Consistent with most of the earlier studies that have shown significant tracking of office BP from childhood to adulthood, we found moderate-to-relatively high tracking stability for office BP in this study. Little is known about the long-term tracking stability of ABP, especially during the important transition period from childhood to early adulthood. Lurbe et $a l . .^{38}$ found good reproducibility of ABP monitoring in 30 healthy normotensive children. O'Sullivan et al. ${ }^{39}$ found high correlation coefficients for 24-h SBP (0.79) and DBP (0.55) in a study of 50 teenagers in whom ABP measurements were repeated 1 year later. On the basis of a 5-year follow-up of ABP in 162 healthy older adults, Goldstein et al. ${ }^{40}$ also found relatively high correlation coefficients for ABP (range: 0.62-0.70). It should be 


\begin{tabular}{|c|c|c|c|c|}
\hline & \multicolumn{2}{|c|}{ Negative on family history of EH } & \multicolumn{2}{|c|}{ Positive on family history of $E H$} \\
\hline & Tracking coefficient $(95 \% \mathrm{Cl})$ & P-value & Tracking coefficient (95\% CI) & P-value \\
\hline Daytime DBP & $0.40(0.28,0.53)$ & $<0.001$ & $0.52(0.46,0.58)$ & $<0.001$ \\
\hline Night-time DBP & $0.18(0.06,0.30)$ & $<0.01$ & $0.32(0.26,0.38)$ & $<0.001$ \\
\hline DBP (day-night) & $0.02(-0.10,0.14)$ & NS & $0.12(0.06,0.18)$ & $<0.001$ \\
\hline SBP ((day-night)/day) & $0.01(-0.10,0.13)$ & NS & $0.16(0.10,0.21)$ & $<0.001$ \\
\hline DBP ((day-night)/day) & $-0.01(-0.12,0.10)$ & NS & $0.10(0.04,0.16)$ & 0.001 \\
\hline
\end{tabular}

Abbreviations: ABP, ambulatory blood pressure; DBP, diastolic blood pressure; EH, essential hypertension; NS, not significant; SBP, systolic blood pressure.

Tracking coefficient is the standardized regression coefficient.

aAll the tracking coefficients were adjusted for age, gender and ethnicity.

noted, however, that in these studies that suggest high tracking of ABP, only ABP at the first and the last visits within relatively short periods of follow-up was measured. ${ }^{38-40}$ In this study with up to 12 repeated measurements over a 15 -year period from childhood to early adulthood, we found moderate-to-relatively high tracking stability for all of the ABP measurements. The only earlier study comparing the tracking stability of ABP with that of office BP showed that 24-h ABP tracked better than office BP. ${ }^{39}$ We also found that 24-h ABP generally tracked better than office BP, although office SBP and 24-h SBP tracked equally well. Together with the evidence that $\mathrm{ABP}$ is a better predictor of organ damage, cardiovascular morbidity and mortality than office $\mathrm{BP},{ }^{9-13,41}$ our results highlight the importance of the use of $\mathrm{ABP}$ monitoring in clinical practice and the entire 24-h BP monitoring period in predicting future BP.

Evidence regarding BPV tracking stability over a long time period is lacking. In this study, we found that BPV had much lower tracking coefficients in comparison with $\mathrm{ABP}$ and office BP. Existing evidence indicates that the predictability/reproducibility of BPV is also low during a short time period, ${ }^{40,42,43}$ which is consistent with our results on the low tracking stability of BPV during a long time period. Some studies have suggested that the underlying reason for the low reproducibility of BPV may be frequent behavior changes and the responsiveness of BP to 'external demands and internal homeostatic requirements. ${ }^{44}$ Another possible reason for the low tracking stability of BPV is that BPV is strongly affected by outliers of ABP recordings; however, there is still no gold standard for the ABP editing procedure. ${ }^{34}$ Therefore, more objective criteria to identify a universally accepted editing procedure for $\mathrm{ABP}$ recordings and more suitable methods to properly assess BPV are warranted.

Existing evidence on the tracking stability of the nocturnal BP drop is conflicting; some studies show no reproducibility, ${ }^{20-24}$ whereas others studies have indicate relatively good reproducibility. ${ }^{25-28} \mathrm{On}$ the basis of an investigation of 18 normotensive and 3 unmedicated hypertensive young adults, Dimsdale and Heeren ${ }^{20}$ found no reproducibility of nocturnal BP dipping indexed by the decrease in BP from daytime to night-time levels. In this study, consistent with the study of Dimsdale and Heeren, ${ }^{20}$ we found that the tracking coefficients were quite low (range: 0.07-0.13) for both the absolute difference between daytime and night time, and the night-time BP drop expressed as a proportion of the daytime values. With regard to dichotomous dipping (dipper vs. non-dipper), we found that the odds ratios were also quite low, which indicated that the nocturnal BP drop was not stable over time in youth and young adults, regardless of the index of dipping used.

In earlier studies concerning gender differences in office BP tracking, neither the Tromso Study ${ }^{5}$ nor the Amsterdam Growth and Health Study ${ }^{45}$ found any major differences. In this study, we found that males tracked better than females not only for office BP but also for ambulatory PP. The underlying reason for different tracking in males and females from childhood to adulthood in this study is not fully understood. One possible reason is that BP for females in adolescence or early adulthood is more likely to be influenced by their pubertal circadian activities (for example, menses) resulting in relatively poorer tracking stability than in males.

Although a positive $\mathrm{FH}$ of $\mathrm{EH}$ has been shown to predict higher $\mathrm{BP}$ levels in childhood and hypertension in later life, ${ }^{46}$ most of the earlier studies on tracking of BP failed to adjust for $\mathrm{FH}$ of $\mathrm{EH}$ as a potential confounder. To the best of our knowledge, we are the first to test potential differences on the basis of $\mathrm{FH}$ of $\mathrm{EH}$ in tracking $\mathrm{ABP}$ and the nocturnal BP drop. We found that individuals who had positive FHs of EH had significantly higher tracking stability of daytime and nighttime DBP and all measures of the nocturnal BP drop than those who did not. The potential mechanisms behind this intriguing finding await further clarification.

The existing evidence on ethnic differences in BP tracking from childhood to early adulthood is scarce. Bao et al. ${ }^{47}$ showed similar tracking of BP in EAs and AAs from childhood to early adulthood, with correlation coefficients ranging from 0.36 to 0.50 . In this study, consistent with the study of Bao et al. ${ }^{47}$, we did not find significant ethnic differences in the tracking of office BP, and this lack of ethnic differences in tracking was further extended to ABP, BPV and the nocturnal BP drop.

There are four limitations to this study. First, the pubertal maturation stage may have an effect on the tracking stability of BP, BPV and dipping. According to Daniels et al. ${ }^{48}$ the effect of sexual maturation on BP was dependent on body size. As we addressed the effects of height and BMI in our study, which did not change the tracking coefficients of BP, BPV and dipping, we have at least partly controlled for sexual maturation. Second, the use of Dinamap to measure office BP has been criticized. ${ }^{49}$ This should not have had any influence on the tracking stability of office BP because the same device was used throughout the study. Moreover, in a recent meta-analysis by Chen et al., ${ }^{50}$ an automated BP device was equally good or even better than other devices at predicting long-term DBP tracking from childhood to adulthood. Third, BPV indices in this study represented 20 (daytime)/ 
30 min (night time) intermittent BPV, but not beat-to-beat BPV. Although a study by di Rienzo et al. ${ }^{51}$ showed that BPV obtained by intermittent measurements was not significantly different from that obtained by beat-to-beat measurements when the time period between the intermittent measurements of $\mathrm{ABP}$ ranged from 5 to $20 \mathrm{~min}$, future studies on BPV using beat-to-beat BP measurement are warranted. Fourth, the method used to calculate tracking coefficients in this study differs from that used by others (for example, correlation coefficients). Thus, we should be cautious in generalizing of the magnitude of the tracking coefficients in this study in comparison with those assessed using different methods.

In this study, we observed that office BP and ABP had moderate-torelatively high tracking stability from childhood to early adulthood. The better tracking stability of $24-\mathrm{h} \mathrm{ABP}$ in comparison with office BP established by this study does not suggest that 24-h ABP will be able to identify children who will definitely develop hypertension in their adult life. In combination with the better predictive values of endorgan damage and cardiovascular events of 24-h ABP, however, it does indicate the use of 24-h ABP monitoring in future cardiovascular risk assessment and daily clinical practice. Furthermore, the better tracking stability of 24-h ABP monitoring will increase the acceptance of ABP monitoring as a useful modality for the evaluation of BP levels in children and adolescents. Although BPV and nocturnal dipping have been widely used to predict target-organ damage and cardiovascular events, this study suggests that neither of these measures shows stability over time. This should be emphasized in longitudinal studies using these two measures to predict the development of target-organ damage and cardiovascular outcomes, especially in studies involving pediatric populations.

\section{CONFLICT OF INTEREST}

The authors declare no conflict of interest.

\section{ACKNOWLEDGEMENTS}

This study was supported by the following Grants: (1) HL086530 and HL69999 from the National Heart, Lung and Blood Institute; (2) 0730156N from the American Heart Association.

1 Ware JH, Wu MC. Tracking: prediction of future values from serial measurements. Biometrics 1981; 37: 427-437.

2 Foulkes MA, Davis CE. An index of tracking for longitudinal data. Biometrics 1981; 37: 439-446.

3 Elliott WJ. Blood pressure tracking. J Cardiovasc Risk 1997; 4: 251-256.

4 Fuentes RM, Notkola IL, Shemeikka S, Tuomilehto J, Nissinen A. Tracking of systolic blood pressure during childhood: a 15-year follow-up population-based family study in eastern Finland. J Hypertens 2002; 20: 195-202.

5 Wilsgaard T, Jacobsen BK, Schirmer H, Thune I, Lochen ML, Njolstad I, Arnesen E. Tracking of cardiovascular risk factors: the Tromso study, 1979-1995. Am J Epidemiol 2001; 154: 418-426.

6 Burke V, Beilin LJ, Dunbar D. Tracking of blood pressure in Australian children. J Hypertens 2001; 19: 1185-1192.

7 Kelder SH, Osganian SK, Feldman HA, Webber LS, Parcel GS, Leupker RV, Wu MC, Nader PR. Tracking of physical and physiological risk variables among ethnic subgroups from third to eighth grade: the Child and Adolescent Trial for Cardiovascular Health cohort study. Prev Med 2002; 34: 324-333.

8 Woelk G. Blood pressure tracking from child to adulthood: a review. Cent Afr J Med 1994; 40: 163-169.

9 Parati G, Pomidossi G, Albini F, Malaspina D, Mancia G. Relationship of 24-h blood pressure mean and variability to severity of target-organ damage in hypertension. J Hypertens 1987; 5: 93-98.

10 Appel LJ, Stason WB. Ambulatory blood pressure monitoring and blood pressure selfmeasurement in the diagnosis and management of hypertension. Ann Intern Med 1993; 118: 867-882.

11 Verdecchia P, Porcellati C, Schillaci G, Borgioni C, Ciucci A, Battistelli M, Guerrieri M, Gatteschi C, Zampi I, Santucci A. Ambulatory blood pressure. An independent predictor of prognosis in essential hypertension. Hypertension 1994; 24: 793-801.
12 Mancia G, Parati G. Ambulatory blood pressure monitoring and organ damage. Hypertension 2000; 36: 894-900.

13 Dolan E, Stanton A, Thijs L, Hinedi K, Atkins N, McClory S, Den Hond E, McCormack P, Staessen JA, O'Brien E. Superiority of ambulatory over clinic blood pressure measurement in predicting mortality: the Dublin outcome study. Hypertension 2005; 46: $156-161$.

14 Palatini P, Penzo M, Racioppa A, Zugno E, Guzzardi G, Anaclerio M, Pessina AC. Clinical relevance of nighttime blood pressure and of daytime blood pressure variability. Arch Intern Med 1992; 152: 1855-1860.

15 Frattola A, Parati G, Cuspidi C, Albini F, Mancia G. Prognostic value of 24-h blood pressure variability. J Hypertens 1993; 11: 1133-1137.

16 Verdecchia P, Angeli F, Gattobigio R, Rapicetta C, Reboldi G. Impact of blood pressure variability on cardiac and cerebrovascular complications in hypertension. $\mathrm{Am} \mathrm{J}$ Hypertens 2007; 20: 154-161.

17 Sander D, Kukla C, Klingelhofer J, Winbeck K, Conrad B. Relationship between circadian blood pressure patterns and progression of early carotid atherosclerosis: $\mathrm{A}$ 3-year follow-up study. Circulation 2000; 102: 1536-1541.

18 Verdecchia P, Schillaci G, Guerrieri M, Gatteschi C, Benemio G, Boldrini F, Porcellati C. Circadian blood pressure changes and left ventricular hypertrophy in essential hypertension. Circulation 1990; 81: 528-536.

19 Verdecchia P, Schillaci G, Gatteschi C, Zampi I, Battistelli M, Bartoccini C, Porcellati C. Blunted nocturnal fall in blood pressure in hypertensive women with future cardiovascular morbid events. Circulation 1993; 88: 986-992.

20 Dimsdale JE, Heeren MM. How reliable is nighttime blood pressure dipping? Am J Hypertens 1998; 11: 606-609.

21 Omboni S, Parati G, Palatini P, Vanasia A, Muiesan ML, Cuspidi C, Mancia G. Reproducibility and clinical value of nocturnal hypotension: prospective evidence from the SAMPLE study. Study on Ambulatory Monitoring of Pressure and Lisinopril Evaluation. J Hypertens 1998; 16: 733-738.

22 Mochizuki Y, Okutani M, Donfeng Y, Iwasaki H, Takusagawa M, Kohno I, Mochizuki S, Umetani K, Ishii H, ljiri H, Komori S, Tamura K. Limited reproducibility of circadian variation in blood pressure dippers and nondippers. Am J Hypertens 1998; 11: 403-409.

23 Cuspidi C, Meani S, Salerno M, Valerio C, Fusi V, Severgnini B, Lonati L, Magrini F, Zanchetti A. Reproducibility of nocturnal blood pressure fall in early phases of untreated essential hypertension: a prospective observational study. $J$ Hum Hypertens 2004; 18: 503-509.

24 Cuspidi C, Meani S, Valerio C, Sala C, Fusi V, Masaidi M, Zanchetti A, Mancia G. Reproducibility of dipping/nondipping pattern in untreated essential hypertensive patients: impact of sex and age. Blood Press Monit 2007; 12: 101-106.

25 Kario K, Shimada K. Differential effects of amlodipine on ambulatory blood pressure in elderly hypertensive patients with different nocturnal reductions in blood pressure. $\mathrm{Am}$ $J$ Hypertens 1997; 10: 261-268.

26 Dimsdale JE, von Kanel R, Profant J, Nelesen R, Ancoli-Israel S, Ziegler M. Reliability of nocturnal blood pressure dipping. Blood Press Monit 2000; 5: 217-221.

27 Rahman M, Griffin V, Heyka R, Hoit B. Diurnal variation of blood pressure; reproducibility and association with left ventricular hypertrophy in hemodialysis patients. Blood Press Monit 2005; 10: 25-32.

28 Stenehjem AE, Os I. Reproducibility of blood pressure variability, white-coat effect and dipping pattern in untreated, uncomplicated and newly diagnosed essential hypertension. Blood Press 2004; 13: 214-224.

29 Dekkers JC, Snieder H, Van Den Oord EJ, Treiber FA. Moderators of blood pressure development from childhood to adulthood: a 10-year longitudinal study. J Pediatr 2002; 141: 770-779.

30 Wang X, Poole JC, Treiber FA, Harshfield GA, Hanevold CD, Snieder H. Ethnic and gender differences in ambulatory blood pressure trajectories: results from a 15-year longitudinal study in youth and young adults. Circulation 2006; 114: 2780-2787.

31 Barnes VA, Johnson MH, Dekkers JC, Treiber FA. Reproducibility of ambulatory blood pressure measures in African-American adolescents. Ethn Dis 2002; 12: S3-101-S3-106.

32 Dekkers JC, Treiber FA, Kapuku G, Snieder H. Differential influence of family history of hypertension and premature myocardial infarction on systolic blood pressure and left ventricular mass trajectories in youth. Pediatrics 2003; 111: 1387-1393.

33 Harshfield GA, Barbeau P, Richey PA, Alpert BS. Racial differences in the influence of body size on ambulatory blood pressure in youths. Blood Press Monit 2000; 5: 59-63.

34 O'Brien E, Asmar R, Beilin L, Imai Y, Mallion JM, Mancia G, Mengden T, Myers M, Padfield P, Palatini P, Parati G, Pickering T, Redon J, Staessen J, Stergiou G, Verdecchia P, European Society of Hypertension Working Group on Blood Pressure Monitoring. European Society of Hypertension recommendations for conventional, ambulatory and home blood pressure measurement. J Hypertens 2003; 21: 821-848.

35 Parati G, Bilo G, Vettorello M, Groppelli A, Maronati A, Tortorici E, Caldara G, Mancia G. Assessment of overall blood pressure variability and its different components. Blood Press Monit 2003; 8: 155-159.

36 Twisk WR. Applied Longitudinal Data Analysis For Epidemiology-A Practical Guide. Cambridge University Press: United Kingdom, 2003.

37 Wang Y, Wang X. Re: 'Tracking of cardiovascular risk factors: the Troms $\varnothing$ Study, 1979-1995'. Am J Epidemiol 2002; 155: 1144-1145.

38 Lurbe E, Aguilar F, Gomez A, Tacons J, Alvarez V, Redon J. Reproducibility of ambulatory blood pressure monitoring in children. J Hypertens Supp/ 1993; 11: S288-S289.

39 O'Sullivan JJ, Derrick G, Foxall RJ. Tracking of 24-h and casual blood pressure: a 1-year follow-up study in adolescents. J Hypertens 2000; 18: 1193-1196. 
40 Goldstein IB, Shapiro D, Guthrie D. A 5-year follow-up of ambulatory blood pressure in healthy older adults. Am J Hypertens 2003; 16: 640-645.

41 Sega R, Facchetti R, Bombelli M, Cesana G, Corrao G, Grassi G, Mancia G. Prognostic value of ambulatory and home blood pressures compared with office blood pressure in the general population: follow-up results from the Pressioni Arteriose Monitorate e Loro Associazioni (PAMELA) study. Circulation 2005; 111: 1777-1783.

42 Gerin W, Rosofsky M, Pieper C, Pickering TG. A test of reproducibility of blood pressure and heart rate variability using a controlled ambulatory procedure. J Hypertens 1993; 11: 1127-1131.

43 Palatini P, Mormino P, Canali C, Santonastaso M, de Venuto G, Zanata G, Pessina AC Factors affecting ambulatory blood pressure reproducibility. Results of the HARVEST trial. Hypertension and Ambulatory Recording Venetia Study. Hypertension 1994; 23: 211-216.

44 Ward MM TJ, Johnston DW. Temporal stability of ambulatory cardiovascular monitoring. Ann Behav Med 1994; 16: 12-23.

45 Twisk JW, Kemper HC, van Mechelen W, Post GB. Tracking of risk factors for coronary heart disease over a 14-year period: a comparison between lifestyle and biologic risk factors with data from the Amsterdam Growth and Health Study. Am J Epidemiol 1997; 145: 888-898.
46 Munger RG, Prineas RJ, Gomez-Marin O. Persistent elevation of blood pressure among children with a family history of hypertension: the Minneapolis Children's Blood Pressure Study. J Hypertens 1988; 6: 647-653.

47 Bao W, Threefoot SA, Srinivasan SR, Berenson GS. Essential hypertension predicted by tracking of elevated blood pressure from childhood to adulthood: the Bogalusa Heart Study. Am J Hypertens 1995; 8: 657-665.

48 Daniels SR, Obarzanek E, Barton BA, Kimm SY, Similo SL, Morrison JA. Sexual maturation and racial differences in blood pressure in girls: the National Heart, Lung, and Blood Institute Growth and Health Study. J Pediatr 1996; 129: 208-213.

49 O'Brien E, Waeber B, Parati G, Staessen J, Myers MG. Blood pressure measuring devices: recommendations of the European Society of Hypertension. BMJ 2001; 322: 531-536.

50 Chen X, Wang Y, Appel LJ, Mi J. Impacts of measurement protocols on blood pressure tracking from childhood into adulthood: a meta regression analysis. Hypertension 2008; 51: 642-649.

51 di Rienzo M, Grassi G, Pedotti A, Mancia G. Continuous vs intermittent blood pressure measurements in estimating 24-h average blood pressure. Hypertension 1983; 5: 264-269.

Supplementary Information accompanies the paper on Hypertension Research website (http://www.nature.com/hr) 